\title{
From Viral Infections to Autistic Neurodevelopmental Disorders via Cross-Reactivity
}

\author{
Darja Kanduc ${ }^{1, *}$, Anna Polito ${ }^{2}$ \\ ${ }^{1}$ Department of Biosciences, Biotechnologies and Biopharmaceutics, \\ University of Bari, Bari 70125, Italy; \\ ${ }^{2}$ Complex Structure of Neuropsychiatry Childhood-Adolescence, United \\ Hospitals of Foggia, Foggia 71122, Italy.
}

* Corresponding Author: Darja Kanduc. Email: dkanduc@gmail.com; Tel. +39-3356141668.

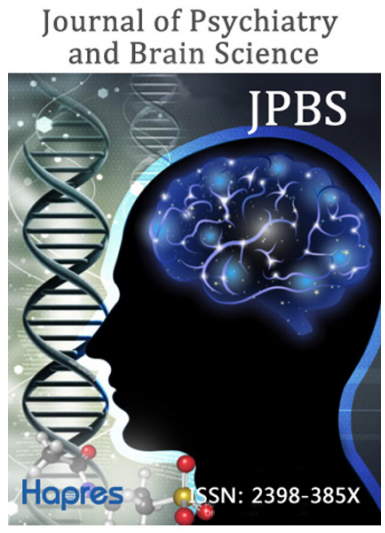

https://jpbs.hapres.com

\section{f OPEN ACCESS}

DOI: 10.20900/jpbs.20180014

Received: 22 November 2018

Accepted: 24 December 2018

Published: December 29, 2018

Copyright: $\odot 2018$ by the authors. Licensee Hapres, London, United Kingdom. This is an open access article distributed under the terms and conditions of the Creative Commons Attribution License (CC BY 4.0, https://creativecommons.org/licenses/by/4.0/).

\begin{abstract}
Objective: Genetic, epigenetic, and environmental factors such as infections have been proposed as potential causes of autism spectrum disorder (ASD). Searching for the molecular mechanism by which infections might contribute to the etiopathogenesis of ASD, we analyze here the hypothesis that immune responses to infectious agents may cross-react with human proteins that, when altered, relate to autistic neurodevelopmental spectrum disorders.
\end{abstract}

Methods: Viral and human proteins were analyzed for peptide sharing using the Pir Peptide Match resource.

Results: We find that: (i) an intense peptide overlap occurs between ASD-related viruses and ASD-related human proteins, and might underlie cross-reactivity scenarios following viral infections; (ii) viral peptide sharing also occurs with Y-linked proteins, in this way highlighting an additional potential cross-reactivity burden that would involve male subjects only; (iii) many shared peptides are also part of epitopes experimentally validated as immunopositive in the human host.

Conclusion: This study offers a cohesive set of data that suggests a contribution of immune cross-reactivity to the genesis of ASD.

Keywords: autism spectrum disorders; viral infections; peptide crossreactivity; autism-related proteins; Y-linked proteins

\section{INTRODUCTION}

There is a clinical and epidemiological consensus that infections may be causally involved in the neurodevelopmental and behavioural disturbances that characterize ASD ${ }^{[1-6]}$. Specifically, a main role in the pathophysiology of ASD has been repeatedly suggested for the activation of the immune system against the infectious agents ${ }^{[7-21]}$ rather than to viral/microbial activities per se, such as, for example, 
subversion of the host protein synthesis machinery ${ }^{[22]}$, manipulation of membrane transport pathways ${ }^{[23]}$, and up-regulation of HLA-E expression with, consequently, suppression of NK cell recognition ${ }^{[24-26]}$.

However, how the immune system may be involved in ASD remains undetermined. The issue is further complicated by the fact that ASD are biased towards males, with ratios of $4: 1$ or higher ${ }^{[27-29]}$, so that analyses of or hypotheses on ASD have to contemplate the male bias.

During last decades, in an attempt to further our understanding of infection-induced diseases, we analyzed sequence identities between viruses and humans ${ }^{[30,31]}$. We pursued the hypothesis that peptide commonality between microbial and human proteins might have the potential to trigger cross-reactions in the human host during infection, thus inducing autoimmune pathologic sequelae ${ }^{[30-37]}$. Here, we test such a hypothesis by analyzing viral pathogens that have been related to ASD ${ }^{[38-51]}$ _namely Borna disease virus, Rubella virus, Measles virus, Influenza A virus, and Mumps virus-and searching for amino acid (aa) sequences common to (i) human proteins that, when altered, have been associated with autistic disorders, and (ii) proteins expressed by Y-linked genes.

\section{METHODS}

The viral proteomes analyzed in the present study are as follows, in order of aa length and with abbreviations, Taxonomy ID, number of proteins, and number of aa in parentheses: Parvovirus B19 ( B19; 10798, 3 proteins, 2006 aa); Borna disease virus (BDV; 928296; 6 proteins; 3014 aa); Rubella virus (RUBV; 11041; 2 proteins; 3179 aa); Measles virus (MeV; 11235; 7 proteins; 4680 aa); Influenza A virus, H1N1 (211044; 13 proteins; 4788 aa); Mumps virus (MuV; 11171; 8 proteins; 4977 aa). Proteomes are described in detail at http://www.uniprot.org ${ }^{[52]}$.

The primary sequence of viral proteins was dissected into hexapeptides overlapped by five residues each other. For example, BDV Envelope glycoprotein p57 (UniProt: P52638; 503 aa) was sequentially dissected into MQPSMS, QPSMSF, PSMSFL, SMSFLI, and so forth until its last hexapeptide LGRWQE, for a total of 498 hexapeptides. Then, each viral hexamer was probed for occurrences within human proteins characterized by being related to ASD or encoded by Y-linked genes.

A set of 138 ASD-related human proteins was randomly retrieved from UniProt database and NCBI (https://www.ncbi.nlm.nih.gov/gene) using 'autism' and 'autistic' as keywords and consisted of 138 proteins listed in Table S1. A set of 44 proteins expressed by Y-linked genes was assembled using data from Skaletsky et al. ${ }^{[53]}$ and UniProt database, and are listed in Table S2. Proteins are indicated by UniProt entry and names.

The immunological potential of the peptide matching was analyzed using the Immune Epitope Database (IEDB; www.iedb.org) database ${ }^{[54]}$. Only epitopes that had been experimentally validated as immunopositive in the human host were considered. Data on brain protein expression were retrieved from https://www.proteinatlas.org/humanproteome ${ }^{[55,56]}$.

\section{RESULTS AND DISCUSSION}

We selected and analyzed five proteomes belonging to infectious agents that have been reported as related to or concomitant with ASD. That is, BDV ${ }^{[38-40]}, \mathrm{RUBV}^{[41-46]}, \mathrm{MeV}^{[41,47,48]}$, Influenza A virus ${ }^{[49-51]}$, MuV ${ }^{[41]}$. As a control, we used Parvovirus B19. B19 is the etiological agent of the infantile fifth disease, preferentially targets the erythroblasts in the bone, and does not appear to be related to ASD ${ }^{[57]}$.

Hexapeptides were used as operational minimal immune determinants in light of a vast scientific literature that documents the crucial roles exerted by peptides 5-6 aa long in immunogenicity and antigenicity ${ }^{[58-85]}$.

\subsection{Hexapeptide sharing between B19, BDV, RUBV, MeV, influenza A virus, and MuV proteomes, and human proteins related to ASD}

Table 1 quantitatively describes the hexapeptide sharing between B19, BDV, RUBV, MeV, Influenza $A$ virus, and $M u V$, and the set of the 138 human proteins related to autism (see Table S1). It can be seen that all of the analyzed viruses share hexamers with human proteins related to ASD. Even if at a lesser extent, the peptide commonality also involves the control B19 virus.

Qualitatively, the viral hexapeptide distribution among the ASD-related proteins is described in Table 2. At first glance, space does not permit a match-by-match discussion of the vast peptide sharing illustrated in Tables 1 and 2 . In synthesis, three main points emerge. Firstly, 96 hexapeptides belonging to the 6 analyzed viral pathogens also occur in 76 out of 138 human proteins associated with $A S D$, in this way indicating a non-stochastical clustering of peptide matches in $55 \%$ of the analyzed human proteins. 
Table 1. Quantitation of the Hexapeptide Sharing between B19, BDV, RUBV, MeV, Influenza A Virus, and MuV Proteomes and ASD-Related Proteins.

\begin{tabular}{lll}
\hline Virus $^{1}$ & Number of Shared Hexapeptides & $\begin{array}{l}\text { Number of ASD-Related Proteins Involved } \\
\text { in the Sharing }\end{array}$ \\
\hline B19 & 12 & 10 \\
BDV & 19 & 16 \\
RUBV & 28 & 28 \\
MeV & 32 & 26 \\
Influenza A virus & 18 & 18 \\
MuV & 33 & 28 \\
\hline
\end{tabular}

${ }^{1}$ Viruses described under Methods and listed according to aa length.

Table 2. Hexapeptide Sharing between B19, BDV, RUBV, MeV, Influenza A Virus, and MuV Proteomes and ASD-Related Human Proteins.

\begin{tabular}{|c|c|c|}
\hline Virus & Shared Peptides ${ }^{1}$ & Human Protein Related to ASD ${ }^{2}$ \\
\hline \multirow[t]{10}{*}{ B19 } & LSSSSS & ANK3. Ankyrin-3 \\
\hline & ALSSSSS; GAGGGG & ARI1B. AT-rich interactive domain-containing protein 1B \\
\hline & PGLNPR & CTTB2. Cortactin-binding protein 2 \\
\hline & GLQSFV & HUWE1. E3 ubiquitin-protein ligase HUWE1 \\
\hline & AGPPQS & MAGA4. Melanoma-associated antigen 4 \\
\hline & IQILKD & NAC2. Sodium/calcium exchanger 2 \\
\hline & GESFVG & NHS. Nance-Horan syndrome protein \\
\hline & SSTPIP & POGZ. Pogo transposable element with ZNF domain \\
\hline & GAGGGG & PPR3F. Protein phosphatase 1 regulatory subunit 3F \\
\hline & SSVASKL & SCN2A. Sodium channel protein type 2 subunit alpha \\
\hline \multirow[t]{16}{*}{ BDV } & VNVTFM & AGRG2. Adhesion G-protein coupled receptor G2 \\
\hline & VELETP & ANK3. Ankyrin-3 \\
\hline & LEDEED & ARX. Homeobox protein ARX \\
\hline & ADLDMD; SLLIGV & CHD8. Chromodomain-helicase-DNA-binding protein 8 \\
\hline & IQGLLD & CUL3. Cullin-3 \\
\hline & SVGVKP & HDAC4. Histone deacetylase 4 \\
\hline & HSYVEL & HNRH2. Heterogeneous nuclear ribonucleoprotein $\mathrm{H} 2$ \\
\hline & FHASLL & K1210. Acrosomal protein KIAA1210 \\
\hline & RLTVLVP & KIRR3. Kin of IRRE-like protein 3 \\
\hline & DPDFND; LLKKLL & MARK1. Serine/threonine-protein kinase MARK1 \\
\hline & EVSFCL & NPRL3. GATOR complex protein NPRL3 \\
\hline & AKLVLL & S12A5. Solute carrier family 12 member 5 \\
\hline & TSSHSS & SETD2. Histone-lysine N-methyltransferase SETD2 \\
\hline & HLPALT; LKSSSL & SHAN3. SH3 and multiple ankyrin repeat domains protein 3 \\
\hline & LKSSSL & TSC2. Tuberin \\
\hline & GPDAGP & V1AR. Vasopressin V1a receptor \\
\hline
\end{tabular}


Table 2. Cont

\begin{tabular}{|c|c|c|}
\hline Virus & Shared Peptides $^{1}$ & Human Protein Related to ASD ${ }^{2}$ \\
\hline \multirow[t]{28}{*}{ RUBV } & DANAVT & ANK3. Ankyrin-3 \\
\hline & QQVALL & ANR11. Ankyrin repeat domain-containing protein 11 \\
\hline & QQPQPP & ARI1B. AT-rich interactive domain-containing protein 1B \\
\hline & RPRPPR & AUTS2. Autism susceptibility gene 2 protein \\
\hline & ASCPAG & BICC1. Protein bicaudal C homolog 1 \\
\hline & EDYRALR & CCD22. Coiled-coil domain-containing protein 22 \\
\hline & RGGSAP & CTND2. Catenin delta-2 \\
\hline & EALRAR & CTTB2. Cortactin-binding protein 2 \\
\hline & AVTAAV & DEPD5. GATOR complex protein DEPDC5 \\
\hline & AVGGGP & DMPK. Myotonin-protein kinase \\
\hline & LRELGS & ERBB2. Receptor tyrosine-protein kinase erbB-2 \\
\hline & AEVRPP & FOXP1. Forkhead box protein P1 \\
\hline & AYGRAL & GBRB1. Gamma-aminobutyric acid receptor subunit beta-1 \\
\hline & PWLFAE & IGSF1. Immunoglobulin superfamily member 1 \\
\hline & PPPAPV & MAP1B. Microtubule-associated protein 1B \\
\hline & AAGHTE & MXRA5. Matrix-remodeling-associated protein 5 \\
\hline & TCSPAS & MYO16. Unconventional myosin-XVI \\
\hline & RCTLPI & NPRL2. GATOR complex protein NPRL2 \\
\hline & EPATLL & NRX1A. Neurexin-1 \\
\hline & AVAPRR & PPR3F. Protein phosphatase 1 regulatory subunit 3F \\
\hline & AVTAAV & REEP3. Receptor expression-enhancing protein 3 \\
\hline & ACICEI & S12A5. Solute carrier family 12 member 5 \\
\hline & QTPAPK & SETD2. Histone-Lys N-methyltransferase SETD2 \\
\hline & AALEEG & SETD5. SET domain-containing protein 5 \\
\hline & PPPPAP & SHAN3. SH3 and multiple ankyrin repeat domains protein 3 \\
\hline & LRGAIA & SL9A9. Sodium/hydrogen exchanger 9 \\
\hline & AAAPAP & STK39. STE20/SPS1-related proline-alanine-rich protein kinase \\
\hline & SLSVPA & TSC2. Tuberin \\
\hline \multirow[t]{26}{*}{$\mathrm{MeV}$} & SRGDIN & ANK3. Ankyrin-3 \\
\hline & RLHRAAI & ANR11. Ankyrin repeat domain-containing protein 11 \\
\hline & PGAPAG & APCL. Adenomatous polyposis coli protein 2 \\
\hline & LLGRVR & CCD22. Coiled-coil domain-containing protein 22 \\
\hline & ILSQGN & CHD8. Chromodomain-helicase-DNA-binding protein 8 \\
\hline & VELLIS & CTTB2. Cortactin-binding protein 2 \\
\hline & KGTGSR & CUL3. Cullin-3 \\
\hline & LKLAAL; RLLDRLVR & DIA1. Deleted in autism protein 1 \\
\hline & LVPQVR & DIA1R. Deleted in autism-related protein 1 \\
\hline & LVDVFL & GLT13. Polypeptide N-acetylgalactosaminyltransferase 13 \\
\hline & FIVSNI & GPHRA. Golgi pH regulator A \\
\hline & LDLLLN & HERC2. E3 ubiquitin-protein ligase HERC2 \\
\hline & LLEVVQ; GRALAE & HUWE1. E3 ubiquitin-protein ligase HUWE1 \\
\hline & PTSSVG & K1210. Acrosomal protein KIAA1210 \\
\hline & TLVSGS & MARK1. Serine/threonine-protein kinase MA RK1 \\
\hline & SIQALS & MXRA5. Matrix-remodeling-associated protein 5 \\
\hline & KEEDEG & MYT1L. Myelin transcription factor 1-like protein \\
\hline & VSNAAL & NHS. Nance-Horan syndrome protein \\
\hline & ELAPYP & PQBP1. Polyglutamine-binding protein 1 \\
\hline & TGSSVE & SCN1A. Sodium channel protein type 1 subunit alpha \\
\hline & TGSSVE; ELLESS & SCN3A. Sodium channel protein type 3 subunit alpha \\
\hline & PTLKKL & SETD2. Histone-lysine N-methyltransferase SETD2 \\
\hline & VYSPSR & SETD5. SET domain-containing protein 5 \\
\hline & ISIQAL & T4S20. Transmembrane 4 L6 family member 20 \\
\hline & EVDGDV & TBL1R. F-box-like/WD repeat-containing protein TBL1XR1 \\
\hline & ELLRLQ; VYWLTI & TEN1. Teneurin-1 \\
\hline
\end{tabular}


Table 2. Cont.

\begin{tabular}{|c|c|c|}
\hline Virus & Shared Peptides ${ }^{1}$ & Human Protein Related to ASD ${ }^{2}$ \\
\hline \multirow[t]{18}{*}{ Influenza A virus } & VPLHQS & ADNP2. Activity-dependent neuroprotector homeobox protein 2 \\
\hline & RTLLAK & APCL. Adenomatous polyposis coli protein 2 \\
\hline & AGVESA & BICC1. Protein bicaudal C homolog 1 \\
\hline & AADADT; TGNLQT & CADM1. Cell adhesion molecule 1 \\
\hline & ERELVR & CUL3. Cullin-3 \\
\hline & TATKRI & DEPD5. GATOR complex protein DEPDC5 \\
\hline & EEEVLT & DMPK. Myotonin-protein kinase \\
\hline & GKVTKS & EF1A2. Elongation factor 1-alpha 2 \\
\hline & AGSSEQ & HUWE1. E3 ubiquitin-protein ligase HUWE1 \\
\hline & LKAEIA & MYO16. Unconventional myosin-XVI \\
\hline & KLRTQI & MYT1L. Myelin transcription factor 1-like protein \\
\hline & TRSGGN & NRX1A. Neurexin-1 \\
\hline & TRSGGN & NRX1B. Neurexin-1-beta \\
\hline & EDFVRQ & NSE3. Non-structural maintenance of chromosomes element 3 homolog \\
\hline & LASLLE & SHAN3. SH3 and multiple ankyrin repeat domains protein 3 \\
\hline & KNDLLE & SLIK2. SLIT and NTRK-like protein 2 \\
\hline & LGKCNI & TEN1. Teneurin-1 \\
\hline & LLQNSQ & ULK4. Serine/threonine-protein kinase ULK4 \\
\hline \multirow[t]{28}{*}{ MuV } & TLMGAE & AGRA2. Adhesion G protein-coupled receptor A2 \\
\hline & PSAGMQN & ARI1B. AT-rich interactive domain-containing protein 1B \\
\hline & NLVARK & CAC1H. Voltage-dependent T-type calcium channel subunit alpha-1H \\
\hline & ASNIVG; GEEGSI & CADM1. Cell adhesion molecule 1 \\
\hline & KTLSNL & CCD22. Coiled-coil domain-containing protein 22 \\
\hline & LGELVR & CYFP1. Cytoplasmic FMR1-interacting protein 1 \\
\hline & ASAVGV & DIA1R. Deleted in autism-related protein 1 \\
\hline & HIRLAD & DMPK. Myotonin-protein kinase \\
\hline & DDLIRY & FAN1. Fanconi-associated nuclease 1 \\
\hline & DNRVAD & GBRB1. Gamma-aminobutyric acid receptor subunit beta-1 \\
\hline & DNRVAD & GBRB3. Gamma-aminobutyric acid receptor subunit beta-3 \\
\hline & LELSEA & HECAM. Hepatocyte cell adhesion molecule \\
\hline & SQSSSS; EIKAAS & HUWE1. E3 ubiquitin-protein ligase HUWE1 \\
\hline & KGASVS & K1210. Acrosomal protein KIAA1210 \\
\hline & LVTCLG & MAGA4. Melanoma-associated antigen 4 \\
\hline & RINNSQ & MEF2C. Myocyte-specific enhancer factor 2C \\
\hline & HLYLAE & MXRA5. Matrix-remodeling-associated protein 5 \\
\hline & ANNHGI; SLFNSG & MYO16. Unconventional myosin-XVI \\
\hline & ASPSSG; AGNISA & NHS. Nance-Horan syndrome protein \\
\hline & SLIPPE & NPRL3. GATOR complex protein NPRL3 \\
\hline & RTCFRI & SCN1A. Sodium channel protein type 1 subunit alpha \\
\hline & EEEEEL & SETD2. Histone-Lys N-methyltransferase SETD2 \\
\hline & LSPLKK; SLPSAG & SETD5. SET domain-containing protein 5 \\
\hline & PLSLAA & SHAN3. SH3 and multiple ankyrin repeat domains protein 3 \\
\hline & ISIQAL & T4S20. Transmembrane 4 L6 family member 20 \\
\hline & TLSTSI & TROP. Trophinin \\
\hline & SLLEME & TSH3. Teashirt homolog 3 \\
\hline & ERRVAS & XPC. DNA repair protein complementing XP-C cells \\
\hline
\end{tabular}

${ }^{1}$ Hepta- and octapeptides formed by overlapping hexapeptides given bold. ${ }^{2}$ Details and references on human proteins at www.uniprot.org. 
Secondly, in light of the fact that the probability of a hexapeptide occurring once in a protein is 1 out of $20^{6}$, the viral vs human peptide overlap reported in Table 2 largely exceeds mathematical expectation. As a note a latere, we observe that this unexpected high peptide matching may be explained by the evolutionary role played by viruses in the origin of the eukaryotic nucleus ${ }^{[86]}$.

Then, as a third point, it was found that human proteins related to ASD and sharing peptides with the analyzed viruses are mostly expressed in the brain. Limiting our analysis to a few examples-i.e., ARI1B, CTTB2, HUWE1, SETD2, and SHAN3 proteins-we find that:

- AT-rich interactive domain-containing protein 1B (ARI1B) shares the viral peptides ALSSSSS, GAGGGG, QQPQPP, and PSAGMQN (Table 1). ARI1B has been detected in embryonic stem cells ${ }^{[87]}$ where it is involved in transcriptional repression ${ }^{[88]}$. ARI1B has essential roles in dendritic arborization and spine morphology of developing pyramidal neurons ${ }^{[89]}$. Haploinsufficiency of ARID1B has been related to corpus callosum abnormalities, intellectual disability, speech impairment, and autism ${ }^{[00,91]}$.

- Cortactin-binding protein 2 (CTTB2) shares the viral peptides PGLNPR, EALRAR, and VELLIS (Table 2). CTTB2 regulates the dendritic spine distribution of cortactin in hippocampal neurons ${ }^{[92]}$. Of note, dendritic spines are the major locations of excitatory synapses in mammalian brains ${ }^{[93]}$.

- The ubiquitin ligase HUWE1 shares the viral peptides GLQSFV, AGSSEQ, SQSSSS, EIKAAS, LLEVVQ, and GRALAE (Table 2). HUWE1 promotes neurogenesis ${ }^{\left[{ }^{[9,95]}\right.}$. HUWE1dependent degradation of the transcriptional regulator atonal homolog 1 (Atoh1) is required for normal differentiation of cerebellar granule neuron progenitor cells ${ }^{[96]}$.

- Histone-Lys N-methyltransferase SETD2 shares the viral peptides TSSHSS, QTPAPK, EEEEEL, and PTLKKL (Table 2). SETD2 is the main enzyme generating histone $\mathrm{H} 3$ trimethylation at lysine 36, a specific tag for epigenetic transcriptional regulation. SETD2 mutation was detected in a child with autism, intellectual disabilities and epilepsy ${ }^{[97]}$. SETD2 alterations may lead to alterations of epigenetic mechanisms that are critical in neural development ${ }^{[98]}$.

- SH3 and multiple ankyrin repeat domains protein 3 (SHAN3) shares the viral peptides HLPALT, LKSSSL, PPPPAP, LASLLE, and PLSLAA (Table2). SHAN3 is a postsynaptic density protein that contributes to orchestrate the dendritic spine and synapse formation, has a critical role in neuronal morphogenesis in placodal neurons ${ }^{[99]}$, and participates in the regulation of developing neurons growth cone motility and the NMDA receptor-signaling ${ }^{[100]}$.

\subsection{Hexapeptide sharing between B19, BDV, RUBV, MeV, influenza A virus, and MuV proteomes and human Y-chromosomal proteins}

The human $Y$ chromosome contains a male-specific non-recombining region with 27 protein-coding genes (Table S2) ${ }^{[53]}$. The peptide sharing between the analyzed viruses and the Y-chromosomal proteins is shown in Table 3. It can be seen that 7 Y-linked proteins namely: KDM5D (SMCY), PC11Y, TBL1Y, TXNG2, USP9Y, UTY (KDM6C), and ZFY - share hexa-/heptapeptides with all of the potential viral pathogens analyzed here, B19 excluded (Table 3).

The 7 Y-linked proteins are widely expressed in the brain. Specifically:

- lysine-specific demethylase 5D (KDM5D aka protein SMCY aka $\mathrm{H}-\mathrm{Y}$ antigen) specifically demethylates trimethylated histone $\mathrm{H} 3$ lysine $4(\mathrm{H} 3 \mathrm{~K} 4 \mathrm{me} 3)^{[101]}$ and is associated with gene activation ${ }^{[102]}$. H3K4me3 is expressed in neonatal male cortex/hippocampus at levels more than 3,000 times higher than in females as shown by reverse transcription with quantitative PCR (RT-qPCR) ${ }^{[103]}$. Male-specific KDM5D expression has been detected in post-mortem human brain ${ }^{[104]}$;

- protocadherin-11 Y-linked protein (PC11Y) is involved in cell-cell interactions and is critical in the development of the central nervous system. PC11Y is expressed strongly in fetal brain and brain (cortex, amygdala, thalamus, substantia nigra, hippocampus, caudate nucleus and corpus callosum) ${ }^{[105,106]}$;

- transducin beta-like protein 1Y (TBL1Y) is expressed in fetal brain and prostate ${ }^{[53]}$. TBL1Y may contribute to the variation in male-specific phenotypes ${ }^{[107]}$. Recently, a role of TBL1Y during cardiac differentiation of human embryonic stem cells has been proposed. It was seen that a reduced TBL1Y cellular level influenced cardiac differentiation and increased the probability of impaired contractions ${ }^{[108]}$. Then, it is pertinent to recall that subjects with autism are at risk for heart problems ${ }^{[109-111]}$;

- putative gamma-taxilin 2 (TXNG2) is ubiquitously expressed ${ }^{[53]}$; 
- ubiquitin carboxyl-terminal hydrolase FAF-Y (USP9Y) might stabilize through de-ubiquitination a specific target protein that is important for male germ cell development ${ }^{[112,113]}$. USP9Y expression has been found in post-mortem human brain ${ }^{[104]}$ and during neurodevelopment in mouse brain ${ }^{[133]}$;

- histone demethylase UTY (also known as KDM6C) catalyzes demethylation of histone $\mathrm{H} 3$ lysine 27 (H3K27) ${ }^{[114]}$ that, in the trimethylated form (H3K27me3), is involved in gene silencing ${ }^{[115]}$. In the mouse brain, UTY has a male-specific high expression in the paraventricular nucleus of the hypothalamus ${ }^{[116]}$. UTY has been detected in post-mortem human brain ${ }^{[104]}$;

- the transcriptional activator zinc finger Y-chromosomal protein (ZFY) is transcribed in hypothalamus, and frontal and temporal cortex of adult human brain ${ }^{[117]}$.

Table 3. Hexapeptide Sharing between B19, BDV, RUBV, MeV, Influenza A Virus, and MuV Proteomes and Y-Chromosomal Proteins.

\begin{tabular}{lll}
\hline Virus & Shared Peptides $^{1}$ & Y-Chromosomal Protein \\
\hline B19 & - & - \\
BDV & PSRGDS & PC11Y. Protocadherin-11 Y-linked \\
& SLVDSL & USP9Y. Probable ubiquitin carboxyl-terminal hydrolase FAF-Y \\
RUBV & SPGLLR & KDM5D. SMCY. Lysine-specific demethylase 5D. SMCX \\
& IVAVIP & TBL1Y. F-box-like/WD repeat-containing protein TBL1Y \\
& RAIQKII & USP9Y. Probable ubiquitin carboxyl-terminal hydrolase FAF-Y \\
& DAAVAA & ZFY. Zinc finger Y-chromosomal protein \\
MeV & KLAALC & TXNG2. Putative gamma-taxilin 2 \\
& DKKVDT & USP9Y. Probable ubiquitin carboxyl-terminal hydrolase FAF-Y \\
Influenza A virus & SSIGKV & UTY. KDM6C. Histone demethylase UTY \\
MuV & SKTFLKK & KDM5D. SMCY. Lysine-specific demethylase 5D. \\
& LQHLEQ & UTY. KDM6C. Histone demethylase UTY \\
\hline
\end{tabular}

${ }^{1}$ Heptapeptides formed by 2 overlapping hexapeptides given bold. ${ }^{2}$ Details on Y-chromosomal proteins at www.uniprot.org and in Ref. ${ }^{[53]}$.

\subsection{Immunologic potential of the viral peptides shared with human proteins related to ASD or expressed by Y-linked genes}

The viral vs human peptide overlap illustrated in Tables 1-3 also has an immunologic potential.
Indeed, Table 4 shows that many shared peptides are part of immunopositive epitopes cataloged at IEDB ${ }^{[54]}$.

Table 4. Immunopositive Epitopes Containing Sequences Shared between B19, BDV, RUBV, MeV, Influenza A Virus, and MuV Proteomes and ASD-Related or Y-Linked Proteins.

\begin{tabular}{ll|ll|ll}
\hline IEDB ID $^{1}$ EPITOPES $^{2}$ & IEDB ID $^{1}$ EPITOPES $^{2}$ & IEDB ID $^{1}$ & EPITOPES $^{2}$ \\
\hline 1848 & aiakledakelless & 87732 & qtpapkpsrappqqpqpprmqtgr & 437698 & gpgripppppapy \\
4375 & asdvetaeggeihellrlq & 87776 & ragltagasqsrrprppr & 438262 & iplppppapety \\
4376 & asdvetaeggeihellrlqsr & 97279 & eqmagsseqaaeameia & 442782 & argaalalllfg \\
11286 & edakellessdqilr & 97289 & etyvlsiipsgplkaeiaqkledvfagkn & 451565 & aaapapapa \\
12901 & ekvtgtdleliqilkdhyni & 97293 & evltgnlqtlkirvhegyeeftmvgrratailr & 451566 & aaapappaa \\
13126 & elklaalchgedsit & 97452 & Ikndllenlq & 452570 & apaaapapa \\
14641 & evdgdvklssnlvil & 97554 & plkaeiaqrledvfagk & 461930 & aevdgdvkl \\
19737 & gggagaggagaggggr & 97694 & tlelrsgywairtrsggn & 462034 & grlvpqvrvid \\
20971 & gllaccakclyylrgaiapr & 97740 & vlasttakameqmagsseqa & 470109 & rprpprpepppglm \\
\hline
\end{tabular}


Table 4. Cont.

\begin{tabular}{|c|c|c|c|c|c|}
\hline IEDB ID ${ }^{1}$ & EPITOPES ${ }^{2}$ & IEDB ID ${ }^{1}$ & EPITOPES $^{2}$ & IEDB ID ${ }^{1}$ & EPITOPES $^{2}$ \\
\hline 20972 & gllacsakclyyLRGAIApr & 97766 & wairTRSGGNtnqqrasa & 470110 & RPRPPRpepppglma \\
\hline 21686 & gpLKAEIAqrle & 97779 & ymlERELVRktrflpva & 476328 & atlpsSPGLLR \\
\hline 21912 & gqlsdhphALSSSSShaepr & 106084 & rprspsSQSSSSgspprrp & 489419 & yLLKKLLql \\
\hline 22542 & gstkscarTLVSGSf & 119022 & $\begin{array}{l}\text { sSQSSSSgspprrpppgrrpffhpvge } \\
\text { adyfeyhqe }\end{array}$ & 504031 & $\begin{array}{l}\text { prspsSQSSSSgspprr } \\
\text { ppp }\end{array}$ \\
\hline 35591 & $\begin{array}{l}\text { lelrsrywairTRSGGNtn } \\
\text { qqras }\end{array}$ & 119788 & cPLSLAAqld & 507907 & RPRPPRpldshl \\
\hline 36538 & ligllaiagiRLHRAAlytaeihk & 120221 & ssssagggggGAGGGGggggsgg & 508324 & spKGASVSi \\
\hline 37232 & LLEVVQsdqsqsgltfasr & 127270 & tyvlsivpsgpLKAEIAqrl & 509573 & eAAAPAPtv \\
\hline 37300 & IlfsilgLSSSSSis & 127692 & ifkiekGKVTKSielna & 509875 & IpLSSSSSv \\
\hline 39061 & IrdpisaeISIQALS & 128243 & AGSSEQaaeamevasqa & 517071 & gPGAPAGaqpaqpp \\
\hline 40581 & IvsgsfgnrfILSQGNli & 128743 & glKNDLLEnlqayqkrm & 517072 & gPGAPAGaqpaqpps \\
\hline 40826 & lyksnhnnVYWLTIp & 129032 & kameqmAGSSEQaaeam & 534817 & yivtdqkPLSLAA \\
\hline 43219 & nalypMSPLLQeclr & 129920 & sivpsgpLKAEIAqrle & 534818 & yivtdqkPLSLAAg \\
\hline 46150 & ntlelrsrywairTRSGGNt & 130187 & vaymIERELVRktrflp & 540558 & ptILSQGNrfcapder \\
\hline 48376 & pLKAEIAqrledv & 131276 & wheaqpSPGLLR & 540650 & yaiggsasptILSQGN \\
\hline 48856 & ppppeerqetrsQTPAPKps & 143551 & stlelrsrywairTRSGGNt & 540949 & agglggGAGGGGdhad \\
\hline 52333 & qshgqlsdhphALSSSSSha & 145868 & lelrsrywairTRSGGNt & 544452 & ppgapsapAAAPAPaa \\
\hline 52523 & qtgRGGSAPrpelgpptn & 150995 & hLGKCNlagwilgnp & 549187 & IlqEEEEEL \\
\hline 52588 & $\begin{array}{l}\text { QTPAPKpsrappQQPQPP } \\
\text { rmqtgrg }\end{array}$ & 164390 & sstglKNDLLEnlqayqk & 552594 & htkLSSSSSitltlp \\
\hline 53963 & rgrgrgekrprspsSQSSSS & 170345 & anptILSQGNrf & 562078 & aLLEVVQsggkniel \\
\hline 54638 & RLLDRLVRI & 173446 & tILSQGNrfhap & 569127 & grLKAEIAr \\
\hline 54946 & $\begin{array}{l}\text { rmqtgRGGSAPrpelgpptnp } \\
\text { fqaava }\end{array}$ & 179908 & smDAAVAAI & 571902 & eELLRLQql \\
\hline 55937 & $\begin{array}{l}\text { rsQTPAPKpsrappQQPQP } \\
\text { Prmqt }\end{array}$ & 181520 & ynpytrsIQILKD & 574167 & kLLEVVQpcl \\
\hline 56752 & saeISIQALSyalgg & 182182 & irlradTLMGAElaarpeyr & 592219 & gdpeeeeEEEEELvd \\
\hline 58175 & sgplkaeiaqkledvfagkn & 188697 & klcklrgvaplhlgkcniag & 593877 & aagaalalalw \\
\hline 58176 & sgplkaeiaqrle & 202816 & ataavtaavk & 594430 & assppagpppppapalvg \\
\hline 58177 & sgplkaeiaqrledv & 227311 & krprspssqssssgs & 599581 & Ltvlvprvw \\
\hline 59546 & slvgidpfkllqnsqvyslirp & 227587 & ssqssssgspprrpp & 601005 & rlrelgslvw \\
\hline 59548 & slvgidpfrllqnsqvfsli & 239959 & lagaggggaavtv & 601256 & rsvssqssssvs \\
\hline 60889 & ssaglkndllenlqayqkrm & 245808 & aakapapkaaapapk & 614836 & dsssvaskv \\
\hline 63973 & tgtdleliqilkdhynisld & 252233 & akapapkaaapapka & 620205 & kslligvfk \\
\hline 67496 & tyvlsiipsgplkaeiaqrl & 255133 & apapkaaapapkaaa & 621015 & lelseavlptmta \\
\hline 72315 & wdleatgaciceipt & 255442 & apkaaapapkaaaaa & 629659 & avppppapl \\
\hline 79398 & $\begin{array}{l}\text { srappppeerqesrsqtpapkpsr } \\
\text { app }\end{array}$ & 316384 & kapapkaaapapkaa & 632869 & islippeerw \\
\hline 79399 & $\begin{array}{l}\text { srappqqpqpprmqtgrggsap } \\
\text { rpelg }\end{array}$ & 348636 & papkaaapapkaaaa & 638702 & vpvavtaav \\
\hline 79544 & fapwdleatgaciceiptdv & 419951 & margaalal & 641923 & dyfkdlcgpdagpig \\
\hline 79784 & dpfrllqnsqvys & 434859 & argaalalllf & 645191 & iqriplppppapety \\
\hline 79844 & gplkaeiaqrled & 434943 & artllaknl & 650955 & tpkdqfiiaygglrgaia \\
\hline
\end{tabular}

${ }^{1}$ Epitopes listed according to the IEDB ID number. ${ }^{2}$ Peptide sequences shared between viruses and human proteins in capital letters. 
Again, the high number of epitopes containing the shared peptide sequences precludes a detailed epitope-by-epitope discussion. However, a special attention has to be drawn to the peptide RLLDRLVR shared between MeV and the human Deleted in Autism protein 1 (DIA1). In fact, the peptide RLLDRLVR corresponds to the epitope IEDB ID 54638 (Table 4 ) that was shown to be responsive in $80 \%$ of 5 HLA-A2-positive adults revaccinated with measlesmumps-rubella vaccine ${ }^{[118]}$.

Another point calling for attention is that hexapeptide analyses underestimate by one order of magnitude the potential cross-reactivity that may be evoked by immune responses following infections. As a matter of fact, also a pentapeptide can represent a minimal immune unit endowed with immunogenicity and antigenicity ${ }^{[58-86]}$. And, in addition, discontinuous pentapeptide epitopes have been reported in IEDB database such as the Influenza $A$ hemagglutinin conformational epitope $\mathrm{P}^{134} \mathrm{~S}^{137} \mathrm{~K}^{177} \mathrm{Y}^{180} \mathrm{~T}^{183}$ (IEDB ID: 164481). Hence, expanding the similarity analyses to (dis)continuous pentapeptides would generate a viral vs human cross-reactivity scenario even more massive than that displayed in Tables 1-4.

\subsection{ASD-related and Y-chromosomal proteins involved in the viral peptide}

\section{overlap: expression in the human brain}

Taken together, Tables 1-4 factually support the hypothesis that, following active infections by the viral pathogens analyzed here, the consequent antiviral immune responses might cross-react with ASDrelated and/or Y-linked proteins expressed in the human brain. However, it is incumbent to observe that the brain expression data reported above have been mainly obtained in animal models, and using microarray analyses, quantitative real-time PCR, and in situ hybridization technologies. Actually, it is well-known that transcript abundances only partially predict protein abundances ${ }^{[119,120]}$. Consequently, since a conditio sine qua non for a cross-reaction to occur is a sufficient level of antigenemia, the Human Protein Atlas resource (https://www.proteinatlas.org/) ${ }^{[55,56]}$ was searched for data on the expression level in the brain of the proteins discussed above. Results are reported in Fig. 1 that shows that the ASD-related proteins ARI1B, CTTB2, HUWE1, and SHAN3 have an expression level from medium to high in the nervous system cells (panel A) and that, among the Y-chromosomal proteins, TBL1Y has a high protein expression level in almost all nervous system cells (panel B). Expression in peripheral nerve cells was low or absent. Data on KDM5D, USP9Y, and TXNG2 proteins were pending or not available at the time of the present study.

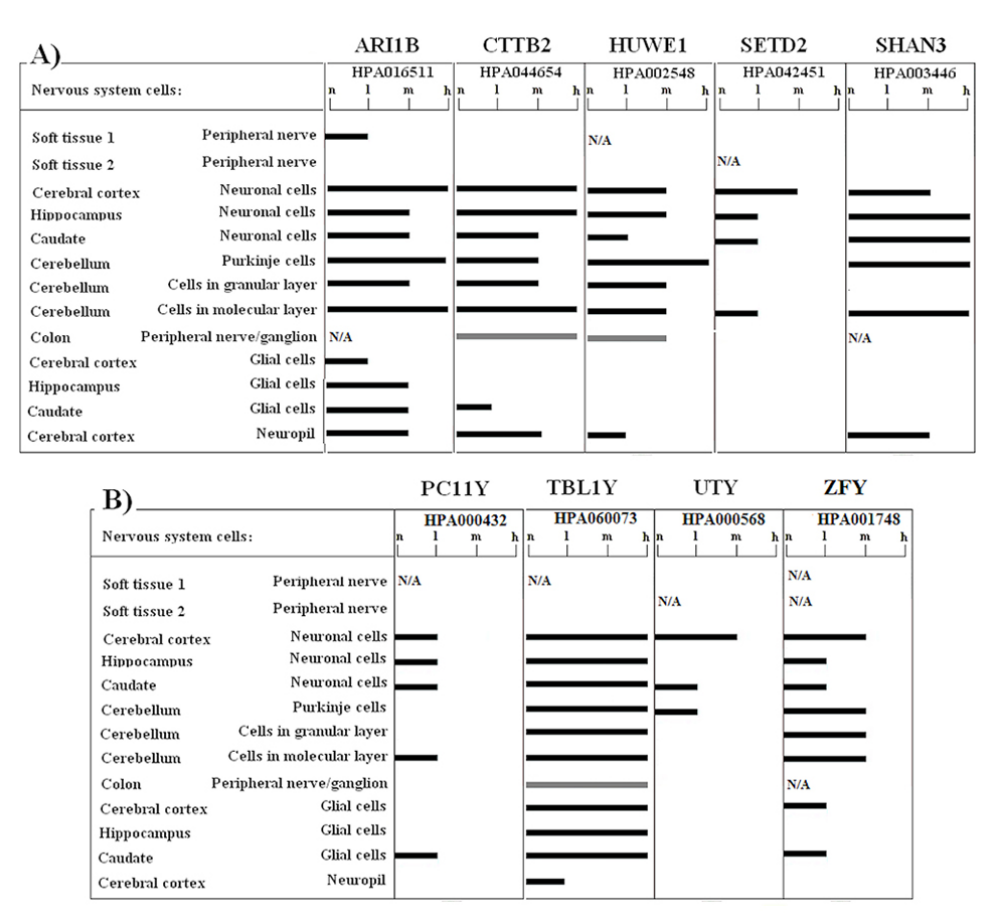

Fig. 1 Expression in the human brain of (A) ASD-related proteins ARI1B, CTTB2, HUWE1, SETD2, and SHAN3, and (B) Y-chromosomal proteins PC11Y, TBL1Y, UTY, and ZFY. Estimates of the protein expression are-n: not detected; I: low; m: medium; h: high. Grey bars refer to expression in peripheral nerve/ganglion. Antibodies are described at www.proteinatlas.org. Images and data from www.proteinatlas.org ${ }^{[55,56]}$. Further details at www.proteinatlas.org. 


\section{CONCLUSIONS}

ASD is of unknown etiology. Genetic components such as mutations ${ }^{[121]}$, epigenetic disorders such as altered methylaton ${ }^{[122]}$, abnormal cytokine profile where inflammatory signals dominate ${ }^{[15]}$, and environmental factors such as pollutants ${ }^{[123]}$ or immune responses to infections ${ }^{[7-21]}$ appear to contribute to ASD. However, whichever it may be the invoked causal factor, the mechanism(s) at the basis of ASD remain unsettled.

Here, we hypothesized that immune responses against infectious viral agents might have the potential to cross-react with proteins that, when altered, are related to autism. Actually, Tables 1, 2 and 4, and Fig. $1 \mathrm{~A}$ document an ample and potentially immunologic peptide matching of B19, BDV, RUBV, MeV, Influenza $A$ virus, and MuV with ASD-related proteins, thus supporting the possibility of a causal connection between infection and neurodevelopmental diseases through cross-reactivity. Very much the same consideration applies to data from Tables 3 and 4 , and Fig. 1B that highlight peptide overlaps between viral and Y-chromosomal proteins. In this case, the potential cross-reactivity burden specifically involves male subjects, so determining a higher male susceptibility to neurodevelopmental disorders.

It has to be underlined that ASD comprehends autism, childhood disintegrative disorder and Asperger syndrome that are characterized, in different combinations and at various level of intensity, by symptoms such as impaired capacity for interactions, a restricted repertoire of interests, stereotyped repetitive activities, and decreased intellectual ability ${ }^{[1]}$. Hence, the here described numerous brain

\section{REFERENCES}

1. National Collaborating Centre for Mental Health (UK). Autism: the management and support of children and young people on the autism spectrum. Leicester (UK): British Psychological Society. (NICE Clinical Guidelines, No. 170). Available from: https://www.ncbi.nlm.nih.gov/ books/NBK299062/2013. Accessed 2018 March 1.

2. Hornig M, Mervis R, Hoffman K, Lipkin WI. Infectious and immune factors in neurodevelopmental damage. Mol Psychiatry. 2002; 7: S34-S35.

3. Karim S, Mirza Z, Kamal MA, Abuzenadah AM, Azhar El, Al-Qahtani MH, et al. The role of viruses in neurodegenerative and neurobehavioral diseases. CNS Neurol Disord Drug Targets. 2014; 13: $1213-1223$. proteins involved in the peptide matching and in the consequent potential cross-reactions might explain the multitude of symptoms that characterize ASD. In addition, the ASD symptomatology and severity may have spatial-temporal patterns, with, for example, in utero infections involving the maternal immune system. In this regard, as a final caveat, it has to be kept in the due account the observation that the maternal immune response in the absence of virus and obtained by using the synthetic double-stranded RNA poly (I:C) is sufficient to cause behavioral changes in the offspring ${ }^{[124]}$. Moreover, the infection outcome in children and adults may depend on previous immune responses following previous encounters with the pathogens ${ }^{[125,126]}$.

In sum, the data support our previous studies ${ }^{[30-37]}$, offer the immune cross-reactivity paradigm as a possible approach for studying autism and neuropsychiatric disorders, and strongly warrant further collaborative research efforts to determine the impact of viral vs human cross-reactivity in the etiology of ASD.

\section{AUTHOR CONTRIBUTIONS}

DK proposed the original idea, developed sequence analyses and wrote the manuscript. AP contributed to the clinical analysis and discussion of the data, and to the writing of the manuscript.

\section{CONFLICTS OF INTEREST}

The authors declare that they have no conflicts of interest.

4. Abdallah MW, Hougaard DM, Nørgaard-Pedersen B, Grove J, Bonefeld-Jørgensen EC, Mortensen EL. Infections during pregnancy and after birth, and the risk of autism spectrum disorders: a registerbased study utilizing a Danish historic birth cohort. Turk Psikiyatri Derg. 2012; 23: 229-235.

5. Hornig M, Weissenböck H, Horscroft N, Lipkin WI. An infection-based model of neurodevelopmental damage. Proc Natl Acad Sci USA. 1999; 96: 12102-12107.

6. Estes ML, McAllister AK. Maternal immune activation: Implications for neuropsychiatric disorders. Science. 2016; 353: 772-777.

7. Blaylock RL, Strunecka A. Immune-glutamatergic dysfunction as a central mechanism of the autism spectrum disorders. Curr Med Chem. 2009; 16: 157-170. 
8. Braunschweig D, Krakowiak P, Duncanson P, Boyce R, Hansen, RL, Ashwood P, et al. Autismspecific maternal autoantibodies recognize critical proteins in developing brain. Transl Psychiatry. 2013; 3: e277.

9. Desai A, Sequeira JM, Quadros EV. Prevention of behavioral deficits in rats exposed to folate receptor antibodies: implication in autism. Mol Psychiatry. 2017; 22: 1291-1297.

10. Edmiston E, Ashwood P, Van de Water J. Autoimmunity, autoantibodies, and autism spectrum disorder. Biol Psychiatry. 2017; 81: 383-390.

11. Elamin NE, Al-Ayadhi LY. Brain autoantibodies in autism spectrum disorder. Biomark Med. 2014; 8: 345-352.

12. Goines P, Haapanen L, Boyce R, Duncanson P, Braunschweig D, Delwiche $L$, et al. Autoantibodies to cerebellum in children with autism associate with behavior. Brain Behav Immun. 2011; 25: 514-523.

13. Mader S, Brimberg L, Diamond B. The role of brainreactive autoantibodies in brain pathology and cognitive impairment. Front Immunol. 2017; 8: 1101.

14. Mead J, Ashwood P. Evidence supporting an altered immune response in ASD. Immunol Lett. 2015; 163: 49-55.

15. Masi A, Quintana DS, Glozier N, Lloyd AR, Hickie IB, Guastella AJ. Cytokine aberrations in autism spectrum disorder: a systematic review and metaanalysis. Mol Psychiatry. 2015; 20(4):440-446.

16. Onore $C$, Careaga $M$, Ashwood $P$. The role of immune dysfunction in the pathophysiology of autism. Brain Behav Immun. 2012; 26: 383-392.

17. Piras IS, Haapanen L, Napolioni V, Sacco R, Van de Water J, Persico AM. Anti-brain antibodies are associated with more severe cognitive and behavioural profiles in Italian children with Autism Spectrum Disorder. Brain Behav Immun. 2014; 38: 91-99.

18. Rout UK, Dhossche DM. A pathogenetic model of autism involving Purkinje cell loss through anti-GAD antibodies. Med Hypotheses. 2008; 71: 218-221.

19. Wills S, Cabanlit M, Bennett J, Ashwood P, Amaral D, Van de Water J. Autoantibodies in autism spectrum disorders (ASD). Ann N Y Acad Sci. 2007; 1107: 79-91.

20. Wills S, Cabanlit M, Bennett J, Ashwood P, Amaral DG, Van de Water J. Detection of autoantibodies to neural cells of the cerebellum in the plasma of subjects with autism spectrum disorders. Brain Behav Immun. 2009; 23: 64-74.
21. Wojcik S, Bernatsky S, Platt RW, Pineau CA, Clarke $A E$, Fombonne É, et al. Risk of autism spectrum disorders in children born to mothers with rheumatoid arthritis: A systematic literature review. Arthritis Care Res. 2017; 69: 1926-1931.

22. Walsh D, Mohr I. Viral subversion of the host protein synthesis machinery. Nat Rev Microbiol. 2011; 9: 860-875.

23. Alix E, Mukherjee S, Roy CR. Subversion of membrane transport pathways by vacuolar pathogens. J Cell Biol. 2011; 195: 943-952.

24. Tomasec P, Braud VM, Rickards C, Powell MB, McSharry BP, Gadola S, et al. Surface expression of HLA-E, an inhibitor of natural killer cells, enhanced by human cytomegalovirus gpUL40. Science. 2000; 287: 1031.

25. Ulbrecht M, Martinozzi S, Grzeschik M, Hengel $H$, Ellwart JW, Pla M, et al. Cutting edge: the human cytomegalovirus UL40 gene product contains a ligand for HLA-E and prevents NK cell mediated lysis. J Immunol 2000; 164: 5019-5022.

26. Wilkinson GW, Tomasec P, Stanton RJ, Armstrong $\mathrm{M}$, Prod'homme V, Aicheler R, et al. Modulation of natural killer cells by human cytomegalovirus. J Clin Virol. 2008; 41: 206-212.

27. Baron-Cohen S, Lombardo MV, Auyeung B, Ashwin E, Chakrabarti B, Knickmeyer R. Why are autism spectrum conditions more prevalent in males? PloS Biol. 2011; 9: e1001081.

28. Werling DM, Geschwind DH. Sex differences in autism spectrum disorders. Curr Opin Neurol. 2013; 26: 146-153.

29. Palmer N, Beam A, Agniel D, Eran A, Manrai A, Spettell C, et al. Association of sex with recurrence of autism spectrum disorder among siblings. JAMA Pediatr. 2017; 171: 1107-1112.

30. Natale C, Giannini T, Lucchese A, Kanduc D. Computer-assisted analysis of molecular mimicry between HPV16 E7 oncoprotein and human protein sequences. Immunol Cell Biol. 2000; 78: 580-585.

31. Kanduc D, Stufano A, Lucchese G, Kusalik A. Massive peptide sharing between viral and human proteomes. Peptides. 2008; 29: 1755-1766.

32. Kanduc D. Peptide cross-reactivity: the original sin of vaccines. Front Biosci. 2012; 4: 1393-1401.

33. Kanduc D. Measles virus hemagglutinin epitopes are potential hotspots for crossreactions with immunodeficiency-related proteins. Future Microbiol. 2015; 10: 503-515. 
34. Kanduc D. Influenza and sudden unexpected death: the possible role of peptide cross-reactivity. Infect Int. Forthcoming 2019.

35. Lucchese G, Kanduc D. The Guillain-Barrè peptide signatures: from Zika virus to Campylobacter, and beyond. Virus Adapt Treat. 2017; 9: 1-11.

36. Lucchese G, Kanduc D. Cytomegalovirus infection: the neurodevelopmental peptide signatures. Curr Drug Discov Technol. 2018; 15: 251-262.

37. Polito A, Polimeno R, Kanduc D. Peptide sharing between Parvovirus B19 and DNA methylating/ histone modifying enzymes. a potential link to childhood acute lymphoblastic leukemia. Int J Ped Child Health. 2017; 1: 29-39.

38. Pletnikov MV, Moran TH, Carbone KM. Borna disease virus infection of the neonatal rat: developmental brain injury model of autism spectrum disorders. Front Biosci. 2002; 7: 593-607.

39. Lancaster K, Dietz DM, Moran TH, Pletnikov MV. Abnormal social behaviors in young and adult rats neonatally infected with Borna disease virus. Behav Brain Res. 2007; 176: 141-148.

40. Honda T, Sofuku K, Matsunaga $H$, Tachibana M, Mohri I, Taniike M, Tomonaga K. Prevalence of antibodies against Borna disease virus proteins in Japanese children with autism spectrum disorder. Microbiol Immunol. 2018. doi: https:// doi.org/10.1111/1348-0421.12603.

41. Singh VK, Lin SX, Newell E, Nelson C. Abnormal measles-mumps-rubella antibodies and CNS autoimmunity in children with autism. J Biomed Sci. 2002; 9: 359-364.

42. Deykin E, Mac Mahon B. Viral exposure and autism. Am J Epidemiol. 1979; 109: 628-638

43. Chess S, Fernandez P, Korn S. Behavioral consequences of congenital rubella. J Pediatr. 1978; 93: 699-703.

44. Hutton J. Does rubella cause autism: a 2015 reappraisal? Front Hum Neurosci. 2016; 10: 25.

45. Singh VK. Phenotypic expression of autoimmune autistic disorder (AAD): a major subset of autism. Ann Clin Psychiatry. 2009; 21: 148-61.

46. Hwang SJ, Chen YS. Congenital rubella syndrome with autistic disorder. J Chin Med Assoc. 2010; 73: 104-107.

47. Dyken PR. Neuroprogressive disease of postinfectious origin: a review of a resurging subacute sclerosing panencephalitis (SSPE). Ment Retard Dev Disabil Res Rev. 2001; 7: 217-225.

48. Singh VK, Jensen RL. Elevated levels of measles antibodies in children with autism. Pediatr Neurol. 2003; 28: 292-294.
49. Fatemi SH, Earle J, Kanodia R, Kist D, Emamian ES, Patterson $\mathrm{PH}$, et al. Prenatal viral infection leads to pyramidal cell atrophy and macrocephaly in adulthood: implications for genesis of autism and schizophrenia. Cell Mol Neurobiol. 2002; 22: 25-33.

50. Atladóttir HÓ, Henriksen TB, Schendel DE, Parner ET. Autism after infection, febrile episodes, and antibiotic use during pregnancy: an exploratory study. Pediatrics. 2012; 130: e1447-1454.

51. Fatemi SH, Folsom TD, Liesch SB, Kneeland RE, Karkhane Yousefi M, Thuras PD, et al. The effects of prenatal $\mathrm{H} 1 \mathrm{~N} 1$ infection at E16 on FMRP, glutamate, GABA, and reelin signaling systems in developing murine cerebellum. J Neurosci Res. 2017; 95: 1110-1122.

52. Chen $\mathrm{C}$, Huang $\mathrm{H}$, Wu $\mathrm{CH}$. Protein bioinformatics databases and resources. Methods Mol Biol. 2017; 1558: 3-39.

53. Skaletsky H, Kuroda-Kawaguchi T, Minx PJ, Cordum HS, Hillier L, Brown LG, et al. The malespecific region of the human $Y$ chromosome is a mosaic of discrete sequence classes. Nature. 2003; 423: 825-837.

54. Vita R, Overton JA, Greenbaum JA, Ponomarenko J, Clark JD, Cantrell JR, et al. The immune epitope database (IEDB) 3.0. Nucleic Acids Res. 2015; 43: D405-D412.

55. Uhlén M, Fagerberg L, Hallström BM, Lindskog C, Oksvold P, Mardinoglu A, et al. Proteomics. Tissue-based map of the human proteome. Science. 2015; 347: 1260419.

56. Thul PJ, Åkesson L, Wiking M, Mahdessian D, Geladaki A, Ait Blal H, et al. A subcellular map of the human proteome. Science. 2017; 356: pii:eaal3321.

57. Kerr JR. The role of parvovirus B19 in the pathogenesis of autoimmunity and autoimmune disease. J Clin Pathol. 2016; 69: 279-291.

58. Niman HL, Houghten RA, Walker LE, Reisfeld RA, Wilson IA, Hogle JM, et al. Generation of protein-reactive antibodies by short peptides is an event of high frequency: implications for the structural basis of immune recognition. Proc Natl Acad Sci USA. 1983; 80: 4949-4953 and references therein.

59. Ewing C, Ebringer R, Tribbick G, Geysen HM. Antibody activity in ankylosing spondylitis sera to two sites on HLA B27.1 at the MHC groove region (within sequence 65-85), and to a Klebsiella pneumoniae nitrogenase reductase peptide (within sequence 181-199). J Exp Med. 1990; 171: 16351647 and references therein. 
60. Schwimmbeck PL, Oldstone MB. Molecular mimicry between human leukocyte antigen B27 and Klebsiella. Consequences for spondyloarthropathies. Am J Med. 1988; 85: 5153 and references therein.

61. Oldstone MB. Molecular mimicry and immunemediated diseases. FASEB J. 1998; 12: 12551265 and references therein.

62. Lee CL, Atassi MZ. Enzymic and immunochemical properties of lysozyme. Accurate definition of the antigenic site around the disulphide bridge 30-115 (site 3 ) by 'surface-simulation' synthesis. Biochem J. 1977; 167: 571-581 and references therein.

63. Reddehase MJ, Rothbard JB, Koszinowski UH. A pentapeptide as minimal antigenic determinant for MHC class I-restricted T lymphocytes. Nature. 1989; 337: 651-653 and references therein.

64. Rothbard JB, Gefter ML. Interactions between immunogenic peptides and MHC proteins. Annu Rev Immuno. 1991; 9: 527-565 and references therein.

65. Liebers V, Raulf M, Mazur G, Modrow S, Baur $X$. Epitope mapping with peptides of Chi $t$ I component III and immunomodulation of the Chi $t$ immune response. J Allergy Clin Immunol. 1993; 92: 334-339 and references therein.

66. Moran E, Simmons C, Vinh Chau N, Luhn K, Wills B, Dung NP, et al. Preservation of a critical epitope core region is associated with the high degree of flaviviral cross-reactivity exhibited by a denguespecific CD4+ T-cell clone. Eur J Immunol. 2008; 38: 1050-1057 and references therein.

67. Godkin AJ, Thomas HC, Openshaw PJ. Evolution of epitope-specific memory CD4(+) T-cells after clearance of hepatitis C virus. J Immunol. 2002; 169: 2210-2214 and references therein.

68. Gulden $\mathrm{PH}$, Fischer $\mathrm{P}$, Sherman NE, Wang W, Engelhard VH, Shabanowitz J, et al. A Listeria monocytogenes pentapeptide is presented to cytolytic T lymphocytes by the H2-M3 MHC class Ib molecule. Immunity. 1996; 5: 73-79 and references therein.

69. Zagury JF, Bernard J, Achour A, Astgen A, Lachgar A, Fall L, et al. HIV-1-induced immune suppression may result from autoimmune disorders including anti-SLWDQ autoantibodies. Biomed Pharmacother. 1993; 47: 93-99 and references therein.

70. Frank A. Immunology and Evolution of Infectious Disease. Princeton, NJ: Princeton University Press, 2002 and references therein.

71. Zeng W, Pagnon J, Jackson DC. The C-terminal pentapeptide of $\mathrm{LHRH}$ is a dominant $B$ cell epitope with antigenic and biological function.
Mol Immunol. 2007; 44: 3724-3731 and references therein.

72. Endo M, Nunomura W, Takakuwa Y, Hatakeyama M, Higashi T. A novel epitope (pentapeptide) in the human hemoglobin beta chain. Hemoglobin. 1998; 22: 321-331 and references therein.

73. Tiwari R, Geliebter J, Lucchese A, Mittelman A, Kanduc D. Computational peptide dissection of Melan-a/MART-1 oncoprotein antigenicity. Peptides. 2004; 25: 1865-1871 and references therein.

74. Kishimoto J, Fukuma Y, Mizuno A, Nemoto TK. Identification of the pentapeptide constituting a dominant epitope common to all eukaryotic heat shock protein 90 molecular chaperones. Cell Stress Chaperones. 2005; 10: 296-311 and references therein.

75. Wasniowska K, Petit-LeRoux Y, Tournamille C, Le van Kim C, Cartron JP, Colin Y, et al. Structural characterization of the epitope recognized by the new anti-Fy6 monoclonal antibody NaM 1852C3. Transfus Med. 2002; 12: 205-211 and references therein.

76. Tanabe S. Epitope peptides and immunotherapy. Curr Protein Pept Sci. 2007; 8: 109-118 and references therein.

77. Plewnia G, Schulze K, Hunte C, Tampé R, Koch J. Modulation of the antigenic peptide transporter TAP by recombinant antibodies binding to the last five residues of TAP1. J Mol Biol. 2007; 369: 95-107 and references therein.

78. Stufano A, Kanduc D. Proteome-based epitopic peptide scanning along PSA. Exp Mol Pathol. 2009; 86: 36-40 and references therein.

79. Kanduc D. Homology, similarity, and identity in peptide epitope immunodefinition. J Pept Sci. 2012; 18: 487-494 and references therein.

80. Raychaudhuri S, Sandor C, Stahl EA, Freudenberg $\mathrm{J}$, Lee HS, Jia X, et al. Five amino acids in three HLA proteins explain most of the association between MHC and seropositive rheumatoid arthritis. Nat Genet. 2012; 44: 291-296 and references therein.

81. Kanduc D. Pentapeptides as minimal functional units in cell biology and immunology. Curr Protein Pept Sci. 2013; 14: 111-120 and references therein.

82. Xiao N, Cao J, Zhou H, Ding SQ, Kong LY, Li JN. Identification of three novel B-cell epitopes of $\mathrm{VMH}$ protein from Vibrio mimicus by screening a phage display peptide library. Vet Immunol Immunopathol. 2016; 182: 22-28 and references therein.

83. El-Turk F, Newby FN, De Genst E, Guilliams T, Sprules T, Mittermaier A, et al. Structural 
effects of two camelid nanobodies directed to distinct C-terminal epitopes on a-Synuclein. Biochemistry. 2016; 55: 3116-3122 and references therein.

84. Cui Z, Zhao MH, Jia XY, Wang M, Hu S, Wang $S$, et al. Antibodies to a5 chain of collagen IV are pathogenic in Goodpasture's disease. J Autoimmun. 2016; 70: 1-11 and references therein.

85. Li Z, Wang D, Gu Y, Song S, He M, Shi J, et al. Crystal structures of two immune complexes identify determinants for viral infectivity and type-specific neutralization of human papillomavirus. MBio. 2017; 8: e00787-e007817 and references therein.

86. Kanduc D. The comparative biochemistry of viruses and humans: an evolutionary path towards autoimmunity. Biol Chem. 2018. doi:10.1515/hsz2018-0271.

87. Kaeser MD, Aslanian A, Dong MQ, Yates JR, Emerson BM. BRD7, a novel PBAF-specific SWI/SNF subunit, is required for target gene activation and repression in embryonic stem cells. J Biol Chem. 2008; 283: 32254-32263.

88. Nagl NG, Wang X, Patsialou A, Van Scoy M, Moran E. Distinct mammalian SWI/SNF chromatin remodeling complexes with opposing roles in cellcycle control. EMBO J. 2007; 26: 752-763.

89. Ka M, Chopra DA, Dravid SM, Kim WY. Essential Roles for ARID1B in dendritic arborization and spine morphology of developing pyramidal neurons. J Neurosci. 2016; 36: 2723-2742.

90. Hoyer J, Ekici AB, Endele S, Popp B, Zweier C, Wiesener A, et al. Haploinsufficiency of ARID1B, a member of the SWI/SNF-a chromatinremodeling complex, is a frequent cause of intellectual disability. Am J Hum Genet. 2012; 90: 565-572.

91. Halgren C, Kjaergaard S, Bak M, Hansen C, El-Schich Z, Anderson CM, et al. Corpus callosum abnormalities, intellectual disability, speech impairment, and autism in patients with haploinsufficiency of ARID1B. Clin Genet. 2012; 82: 248-255.

92. Chen YK, Hsueh YP. Cortactin-binding protein 2 modulates the mobility of cortactin and regulates dendritic spine formation and maintenance. J Neurosci. 2012; 32: 1043-1055

93. Harris KM, Stevens JK. Dendritic CA1 pyramidal cells in the rat hippocampus: serial electron microscopy with reference to their biophysical characteristics. J Neurosci. 1989; 9: 2982-2997.

94. Zhao X, Heng JI, Guardavaccaro D, Jiang R, Pagano M, Guillemot F, et al. The HECTdomain ubiquitin ligase Huwe1 controls neural differentiation and proliferation by destabilizing the N-Myc oncoprotein. Nat Cell Biol. 2008; 10: 643-653.

95. Zhao X, Arca D, Lim WK, Brahmachary M, Carro MS, Ludwig T, et al. The N-Myc-DLL3 cascade is suppressed by the ubiquitin ligase Huwe1 to inhibit proliferation and promote neurogenesis in the developing brain. Dev Cell. 2009; 17: 210-221.

96. Vriend J, Ghavami S, Marzban H. The role of the ubiquitin proteasome system in cerebellar development and medulloblastoma. Mol Brain. 2015; 8: 64.

97. Lumish HS, Wynn J, Devinsky O, Chung WK. Brief Report: SETD2 Mutation in a child with autism, intellectual disabilities and epilepsy. J Autism Dev Disord. 2015; 45: 3764-3770.

98.Rangasamy S, D'Mello SR, Narayanan V. Epigenetics, autism spectrum, and neurodevelopmental disorders. Neurotherapeutics. 2013; 10: 742-756.

99. Kathuria A, Nowosiad $P$, Jagasia R, Aigner $S$, Taylor RD, Andreae LC, et al. Stem cell-derived neurons from autistic individuals with SHANK3 mutation show morphogenetic abnormalities during early development. Mol Psychiatry. 2017; 23: 735-746.

100. Shcheglovitov A, Shcheglovitova O, Yazawa M, Portmann T, Shu R, Sebastiano V, et al. SHANK3 and IGF1 restore synaptic deficits in neurons from 22q13 deletion syndrome patients. Nature. 2013; 503: 267-271.

101. Iwase S, Lan F, Bayliss P, de la Torre-Ubieta L, Huarte M, Qi HH, et al. The X-linked mental retardation gene SMCX/JARID1C defines a family of histone $\mathrm{H} 3$ lysine 4 demethylases. Cell. 2007; 128: 1077-1088.

102. Dhar SS, Lee SH, Chen K, Zhu G, Oh W, Allton K, et al. An essential role for UTX in resolution and activation of bivalent promoters. Nucleic Acids Res. 2016; 44: 3659-3674.

103. Armoskus C, Moreira D, Bollinger K, Jimenez O, Taniguchi S, Tsai HW. Identification of sexually dimorphic genes in the neonatal mouse cortex and hippocampus. Brain Res. 2014; 1562: 2338.

104. Vawter MP, Evans S, Choudary P, Tomita H, Meador-Woodruff J, Molnar M, et al. Genderspecific gene expression in post-mortem human brain: localization to sex chromosomes. Neuropsychopharmacology. 2004; 29: 373-384.

105. Blanco P, Sargent CA, Boucher CA, Mitchell M, Affara NA. Conservation of PCDHX in mammals; expression of human $X / Y$ genes predominantly in brain. Mamm Genome. 2000; 11: 906-914. 
106. Priddle TH, Crow TJ. Protocadherin $11 \mathrm{X} / \mathrm{Y}$ a human-specific gene pair: an immunohistochemical survey of fetal and adult brains. Cereb Cortex. 2013; 23: 1933-1941.

107. Yan HT, Shinka T, Kinoshita K, Sato $Y$, Umeno M, Chen G, et al. Molecular analysis of TBL1Y, a $Y$-linked homologue of TBL1X related with $\mathrm{X}$-linked late-onset sensorineural deafness. J Hum Genet. 2005; 50: 175-181.

108. Meyfour A, Ansari H, Pahlavan S, Mirshahvaladi S, Rezaei-Tavirani M, Gourabi H, et al. Y chromosome missing protein, TBL1Y, may play an important role in cardiac differentiation. J Proteome Res. 2017; 16: 4391-4402.

109. Ming X, Julu PO, Brimacombe M, Connor S, Daniels ML. Reduced cardiac parasympathetic activity in children with autism. Brain Dev. 2005; 27: 509-516.

110. Ming X, Patel R, Kang V, Chokroverty S, Julu PO. Respiratory and autonomic dysfunction in children with autism spectrum disorders. Brain Dev. 2016; 38: 225-232.

111. Pace M, Bricout VA. Low heart rate response of children with autism spectrum disorders in comparison to controls during physical exercise. Physiol Behav. 2015; 141: 63-68.

112. Lee KH, Song GJ, Kang IS, Kim SW, Paick JS, Chung $\mathrm{CH}$, et al. Ubiquitin-specific protease activity of USP9Y, a male infertility gene on the $Y$ chromosome. Reprod Fertil Dev. 2003; 15: 129-33.

113. Xu J, Burgoyne PS, Arnold AP. Sex differences in sex chromosome gene expression in mouse brain. Hum Mol Genet. 2002; 11: 1409-1419:

114. Walport LJ, Hopkinson RJ, Vollmar M, Madden SK, Gileadi C, Oppermann U, et al. Human UTY (KDM6C) is a male-specific $\mathrm{N} \epsilon$-methyl lysyl demethylase. J Biol Chem. 2014; 289: 18302-18313.

115. Dhar SS, Lee SH, Chen K, Zhu G, Oh W, Allton $\mathrm{K}$, et al. An essential role for UTX in resolution and activation of bivalent promoters. Nucleic Acids Res. 2016; 44: 3659-3674.

116. Xu J, Deng X, Watkins R, Disteche CM. Sexspecific differences in expression of histone demethylases Utx and Uty in mouse brain and neurons. J Neurosci. 2008; 28: 4521-4527.

117. Mayer A, Lahr G, Swaab DF, Pilgrim C, Reisert I. The Y-chromosomal genes SRY and ZFY are transcribed in adult human brain. Neurogenetics. 1998; 1: 281-828.

118. Ota MO, Ndhlovu Z, Oh S, Piyasirisilp S, Berzofsky JA, Moss WJ, Griffin DE. Hemagglutinin protein is a primary target of the measles virus-specific HLA-A2-restricted CD8+ $T$ cell response during measles and after vaccination. J Infect Dis. 2007; 195: 1799-1807.

119. Vogel C, Marcotte E. Insights into the regulation of protein abundance from proteomic and transcriptomic analyses. Nat Rev Genet. 2012; 13: 227-232.

120. de Sousa Abreu R, Penalva LO, Marcotte E, Vogel C. Global signatures of protein and mRNA expression levels. Mol Biosyst. 2009; 5: 1512-1516.

121. Ronemus M, lossifov I, Levy D, Wigler M. The role of de novo mutations in the genetics of autism spectrum disorders. Nat Rev Genet. 2014; 15(2):133-141.

122. Loke YJ, Hannan AJ, Craig JM. The Role of Epigenetic Change in Autism Spectrum Disorders. Front Neurol. 2015; 6: 107.

123. Sealey LA, Hughes BW, Sriskanda AN, Guest JR, Gibson AD, Johnson-Williams L, Pace DG, Bagasra O. Environmental factors in the development of autism spectrum disorders. Environ Int. 2016; 88: 288-298.

124. Shi L, Fatemi SH, Sidwell RW, Patterson PH. Maternal influenza infection causes marked behavioral and pharmacological changes in the offspring. J Neurosci. 2003; 23(1):297-302

125. Lucchese G, Kanduc D. Minimal immune determinants connect Zika virus, human Cytomegalovirus, and Toxoplasma gondii to microcephaly-related human proteins. Am J Reprod Immunol. 2017; 77: e12608.

126. Kanduc D, Shoenfeld Y. Inter-pathogen peptide sharing and the Original Antigenic Sin: Solving a paradox. Open Immunol J. 2018; 8: 16-27. 